DOI: https://doi.org/10.24123/jbt.v3i02.2510

\title{
ANALISIS FAKTOR MOTIVASI KERJA KARYAWAN (Studi Kasus pada PT Orela Shipyard)
}

\author{
Liliana Dewi $^{1}$, Michael Christopher Doullos Thorion² \\ ${ }^{1}$ Coressponding author \\ Fakultas Manajemen dan Bisnis Universitas Ciputra, Citraland CBD Boulevard, Surabaya. \\ Email: 'Ldewi@ciputra.ac.id, ${ }^{2}$ mchristopher@student.ciputra.ac.id,
}

\section{Abstract}

PT Orela Shipyard is a family company running the shipping industry. In the two recent years, the company's turnover becomes fluctuated, this change is caused by some factors, one of them is the employee work motivation. SLEp:The purpose of this research is to find out the factors that motivate the employee works of PT Orela Shipyard. The data used are primary data with data collection techniques by using a questionnaire. The sample that is used is 60 employees of PT Orela Shipyard that consist of 30 office employees and 30 shipyard employees with a simple random sampling technique and that are processed by using SmartPLS 3.0 software program. This research uses a first-order construct and second-order construct tests. The results of this research indicate that the variables of work safety, award, achievement, salary, relationship with superiors and work conditions are the factors that motivate the work of the employees at PT Orela Shipyard.

Keywords: achievement, award, relationship with superiors, salary, work conditions, work safety.

\section{Pendahuluan}

PT Orela Shipyard adalah perusahaan keluarga yang telah berdiri sejak 1980, bergerak di industri perkapalan. PT Orela memiliki kantor di Jalan W.R Supratman no 23 Surabaya dan memiliki galangan kapal di pelabuhan Gresik. PT Orela melayani pembuatan dan perbaikan kapal yang rusak di mana target pasar PT Orela adalah BUMN dan perusahaan asing. PT Orela shipyard memiliki 100 karyawan yang terbagi dalam 30 karyawan kantor dan 70 karyawan di galangan kapal.

PT Orela Shipyard sudah melakukan beberapa upaya dalam membuat karyawan PT Orela Shipyard bekerja lebih optimal. Upaya tersebut yaitu dengan mengadakan: rapat tahunan yang 
dilakukan sehari sebelum libur tahun baru, dalam acara ini dilakukan sesi kritik dan saran dari karyawan untuk manajemen, terutama admistrasi, ada pula penghargaan dan apresiasi bagi karyawan. Ini dilakukan supaya karyawan dapat memberi masukan kepada perusahaan dalam pembuatan peraturan dan meningkatkan kebanggaan karyawan bekerja dan menaikan kepercayaan diri karyawan untuk bekerja lebih optimal yang mana berhubungan dengan faktor award dan achievement. Pelatihan bagi karyawan kantor dan galangan agar membangun hubungan kerja yang lebih baik dengan atasannya serta menambah kemampuan karyawan yang mana berhubungan dengan faktor relationship with superiors. Selain memberi THR, salary yang sesuai dengan UMR, PT Orela Shipyard sangat peduli dengan keamanan kerja karyawan sehingga memberikan peralatan kerja yang baik dan aman serta bersertifikasi SNI dengan SOP yang jelas. Bertujuan agar karyawan merasa aman saat bekerja dan memiliki standar hidup yang layak yang mana berhubungan dengan faktor work safety, work condition, dan salary.

Berdasarkan evaluasi yang dilakukan oleh perusahaan, karyawan dinilai belum optimal dalam menjalankan tugas dan tanggung jawabnya. PT Orela mengalami beberapa masalah, diantaranya performa perusahaan yang menurun. Profit perusahaan fluktuatif dikarenakan pengerjaan proyek yang tidak tepat waktu. Pengerjaan proyek yang seharusnya 3-4 bulan pengerjaan, seringkali mundur hingga 5-6 bulan pengerjaan. Hal ini menyebabkan 3 kerugian utama, diantaranya denda kontrak kerja, dimana denda berkisar 3-5\%, kedua biaya operasional meningkat karena upah lembur dan yang terakhir adalah menurunnya kepercayaan konsumen karena perusahaan tidak mampu menyelesaikan pekerjaan dengan baik. Berdasarkan masalah tersebut penelitian ini bertujuan untuk mengetahui faktor-faktor yang mempengaruhi motivasi kerja karyawan PT Orela Shipyard.

\section{Landasan Teori}

Menurut Sutedjo\& Mangkunegara(2018), kinerja dalam perusahaan adalah hasil yang dikeluarkan oleh setiap aspek di dalam perusahaan termasuk karyawan. Jika karyawan memiliki motivasi kerja yang baik maka kinerja perusahaan akan semakin baik. Motivasi kerja berpengaruh positif dan signifikan terhadap kinerja karyawan.

Motivasi kerja adalah sebuah dorongan yang muncul dari dalam diri seseorang yang akan mengarahkan tindakan seseorang dengan tujuan mencapai suatu hasil yang diinginkan (Cahyani et al., 2016). Hal tersebut mengarahkan individual bekerja lebih baik dan bertanggung jawab dalam menjalankan kewajiban di organisasi tersebut. Hasil penelitian adalah faktor sumber daya manusia (SDM) serta peran sertanya dalam perusahaan dan pentingnya motivasi kerja di dalam rumah sakit jiwa.

Faktor Motivasi Kerja (Cahyani et al., 2016) adalah:

a. Work Condition adalah Faktor yang berhubungan dengan lingkungan perusahaan, apakah tersedia fasilitas yang baik atau buruk. Kondisi kerja termasuk dalam jam kerja, batasan kerja, sirkulasi udara dan keamanan. Sebuah lingkungan kerja yang baik membuat karyawan puas dan bangga terhadap perusahaan;

b. Relationship with Superiors adalah Hubungan yang personal serta hubungan kerja antara karyawan dengan atasan, karyawaan yang setingkat. Ini berkaitan dengan interaksi dan diskusi dalam lingkungan kerja dalam waktu istirahat;

c. Work Safety adalah lingkungan organisasi yang nyaman dan aman bagi anggota di dalamnya. Gedung maupun lokasi organisasi tersebut; 
d. Salary adalah Kompensasi di perusahaan, termasuk upah maupun kenaikan gaji serta ekspetasi kenaikan gaji tesebut dan harus ada kejelasan hal-hal yang berhubungan dengan kenaikan gaji dan pemberian bonus;

e. Achievement adalah Pencapaian positif termasuk dalam keberhasilan menyelesaikan tugas sulit tepat waktu, menyelesaikan masalah divisi atau memberi hasil positif pada suatu proyek. Pencapaian yang buruk berlaku sebaliknya dimana terjadi kesalahan pengerjaan dan buruknya pengambilan keputusan;

f. Award adalah Penghargaan dari organisasi dalam bentuk gaji, bonus maupun pengakuan atas pencapaian anggota dalam menyelesaikan tugas dan tanggung jawab.

Variabel work conditions memiliki 3 indikator yaitu kenyamanan bekerja di kantor/galangan, tempat bekerja memiliki kondisi yang baik dan fasilitas yang diberikan kantor memuaskan. Variabel relationship with superiors memiliki 3 indikator yaitu atasan mendorong saya bekerja lebih baik, hubungan baik dengan atasan membuat saya bekerja dengan baik, atasan adalah sosok yang dapat dihandalkan. Variabel work safety memiliki 3 indikator yaitu merasa aman bekerja di perusahaan ini, pekerjaan yang dilakukan adalah pekerjaan yang aman, lokasi di daerah yang aman. Variabel salary memiliki 3 indikator yaitu gaji memicu bekerja lebih giat, gaji memenuhi kebutuhan saya dan bonus memicu saya bekerja lebih giat. Variabel achievement memiliki 3 indikator yaitu kebanggaan bekerja di perusahaan, puas dengan pekerjaan saat ini dan berkontribusi maksimal karena reputasi baik perusahaan.Variabel award memiliki 3 indikator yaitu mendapat apresiasi, atasan memberi pujian dan mendapat pengakuan ketika mencapai target (Cahyani et al., 2016).

Dharma (2018) menyatakan pengaruh motivasi kerja karyawan terhadap performa kerja karyawan di bank daerah Aceh. Tujuan dari jurnal ini membahas dampak motivasi kerja terhadap performa karyawan dan perusahaannya. Populasi pada penelitian ini berjumlah 146 karyawan Bank Aceh dan sampel yang diambil adalah 74 dengan metode kuantitatif. Hasil penelitian adalah motivasi kerja karyawan berperan dalam menaikkan kinerja karyawan serta berdampak pada kinerja perusahaan. Berdasarkan teori tersebut maka hipotesis penelitian adalah:

H1: Work Condition merupakan faktor motivasi kerja karyawan PT Orela Shipyard.

H2: Relationship with Superiorsmerupakan faktor motivasi kerja karyawan PT Orela Shipyard.

H3: Work Safety merupakan faktor motivasi kerja karyawan PT Orela Shipyard.

H4: Salary merupakan faktor motivasi kerja karyawan PT Orela Shipyard.

H5: Achievement merupakan faktor motivasi kerja karyawan PT Orela Shipyard.

H6: Award merupakan faktor motivasi kerja karyawan PT Orela Shipyard.

\section{Metodologi Penelitian}

Metode analisis data yang digunakan untuk penelitian ini adalah analisis faktor. Analisis faktor adalah salah satu teknik yang digunakan dalam memperkecil variabel dimana jumlah yang lebih besar menjadi lebih kecil (Ghozali, 2013). Analisis faktor yang digunakan dalam penelitian ini adalah analisis faktor konfirmatori dengan second order confirmatory. Analisis faktor menggunakan software SMARTPLS. Metode tersebut menggunakan dua tahap pengerjaan, tahap pertama dilakukan dengan menguji konstruk dimensi ke indikator dan tahap pengerjaan kedua adalah konstruk laten ke dimensinya (Ghozali, 2013). Skala Likert yang digunakan yaitu lima poin: (1) sangat tidak setuju, (2) tidak setuju, (3) cukup setuju, (4) setuju, (5) sangat setuju. 
Menurut Abdillah dan Jogiyanto (2015) pada first order contsruct akan dilakukan uji model pengukuran dari konstruk dimensi ke indikatornya sedangkanpada second order construct, dilakukan uji model pengukuran dari konstruk laten ke konstruk dimensinya. Populasi dalam penelitian ini merupakan karyawan dan staff dari PT Orela Shipyard yang berjumlah 100 orang. Responden penelitian ini adalah karyawan PT Orela shipyard yang bekerja di galangan dan kantor, berjumlah 60 karyawan.Sugiyono (2014) menjelaskan bahwa rule of thumb dalam menentukan jumlah sampel di dalam SMARTPLS menjelaskan jumlah pengambilan sampel dengan cara faktor dalam penelitian di kali 10, maka dari itu sampel penelitian $(6 \times 10)=60$ responden.

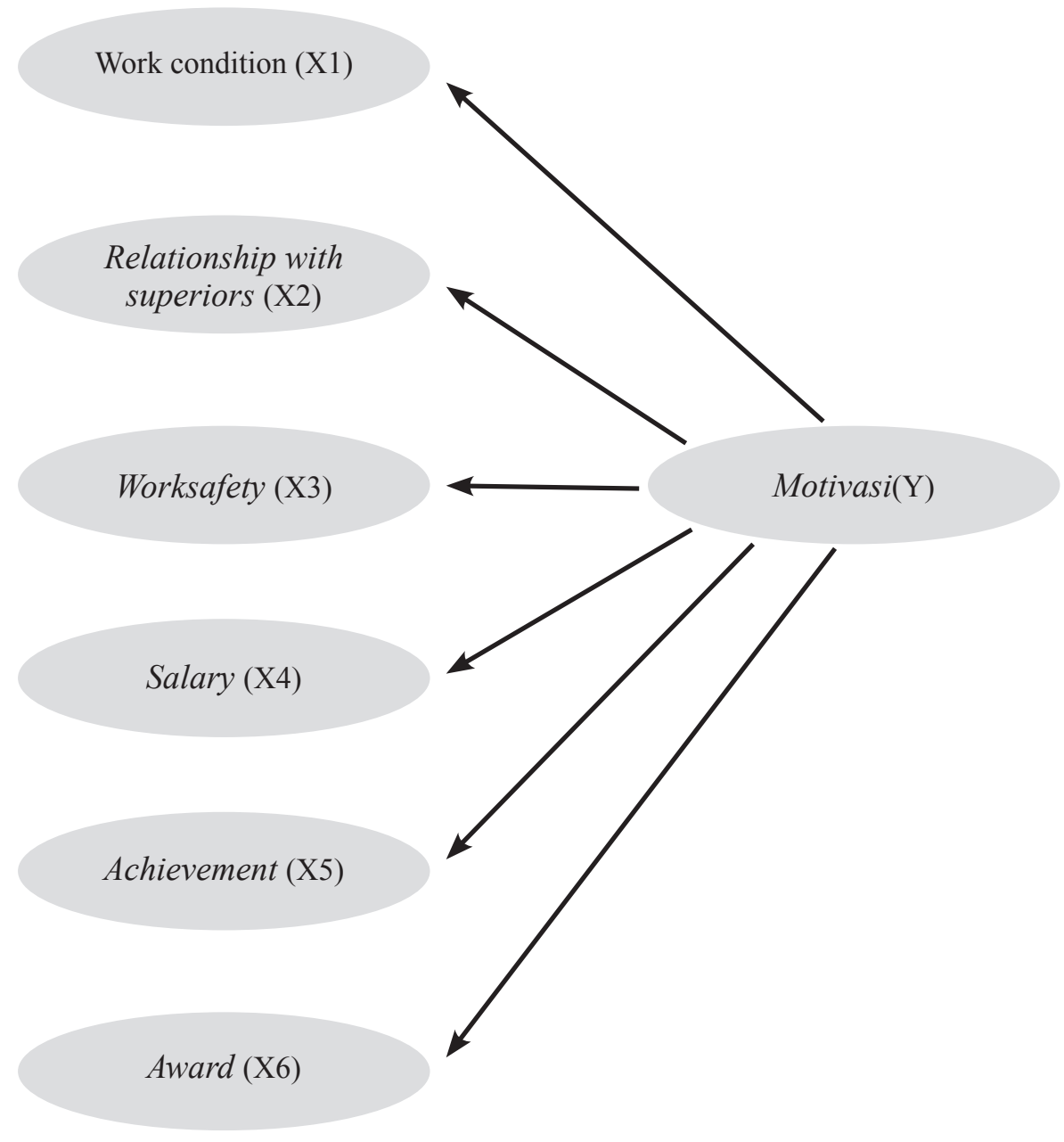

Gambar 1. Model Analisis

Sumber: Data diolah (2018)

\section{Hasil Penelitian dan Pembahasan}

Berdasarkan data yang telah dianalisis, variabel yang dapat mempengaruhi motivasi kerja karyawan PT Orela Shipyard adalahwork condition, relationship with superiors, work safety, salary, achievement, dan award. 
Tabel 1. Nilai Path Coefficient Tiap Variabel

\begin{tabular}{|l|l|l|}
\hline Variabel & Nilai path coefficient & Nilai Koefisien Determinasi \\
\hline Work condition $(x 1)$ & 0.980 & 0,960 \\
\hline Relationship with superiors $(x 2)$ & 0.981 & 0,962 \\
\hline Work safety $(x 3)$ & 0,989 & 0,977 \\
\hline Salary $(x 4)$ & 0.992 & 0,985 \\
\hline Achievement $(x 5)$ & 0,989 & 0,978 \\
\hline Award $(x 6)$ & 0,986 & 0,971 \\
\hline
\end{tabular}

Sumber: Data diolah (2018)

Variabel work conditions merupakan variabel enam tertinggi, dengan nilai path coeffiecient sebesar 0,980 yang mempengaruhi motivasi kerja karyawan dan nilai koefisien determinasi 0,960. Menurut Dharma (2018) faktor yang berhubungan dengan lingkungan perusahaan, apakah tersedia fasilitas yang baik atau buruk. Kondisi kerja termasuk dalam jam kerja, batasan kerja, sirkulasi udara dan keamanan. Sebuah lingkungan kerja yang baik membuat karyawan puas dan bangga terhadap perusahaan.

Variabel Relationship with Superiors merupakan variabel lima tertinggi, dengan nilai path coeffiecient sebesar 0,981 yang mempengaruhi motivasi kerja karyawan dan nilai koefisien determinasi 0,962. Menurut Dharma (2018) hubungan yang personal serta hubungan kerja antara karyawan dengan atasan, karyawaan yang setingkat. Ini berkaitan dengan interaksi dan diskusi dalam lingkungan kerja dalam waktu istirahat. Atasan yang dapat dihandalkan serta memberi contoh bagi karyawan yang lain, hubungan yang baik dengan atasan, memberi motivasi kerja bagi karyawan tersebut.

Variabel Work Safety merupakan variabel kedua tertinggi, dengan nilai path coeffiecient sebesar 0,989 yang mempengaruhi motivasi kerja karyawan dan nilai koefisien determinasi 0,977. Menurut Dharma (2018)lingkungan organisasi yang nyaman dan aman bagi anggota di dalamnya. Gedung maupun lokasi organisasi tersebut. Karyawan akan bekerja lebih optimal jika perusahaan memberikan rasa aman bagi mereka dikala bekerja, dengan memberikan SOP yang jelas, peralatan yang ber-SNI serta lingkungan daerah sekitar kantor atau galangan yang aman.

Variabel salary merupakan variabel tertinggi, dengan nilai path coeffiecient sebesar 0,992 yang mempengaruhi motivasi kerja karyawan dan nilai koefisien determinasi 0,985 . Menurut Dharma (2018)kompensasi di perusahaan, termasuk upah maupun kenaikan gaji serta ekspetasi kenaikan gaji tesebut dan harus ada kejelasan hal-hal yang berhubungan dengan kenaikan gaji dan pemberian bonus. Salary atau gaji merupakan salah satu faktor yang mempengaruhi motivasi kerja karyawan. Gaji menjadi motif utama karyawan bekerja untuk memenuhi kebutuhan pribadi maupun keluarga. Contoh karyawan akan bekerja sangat giat jika perusahaan memberi gaji lebih tinggi dari perusahaan lain karena tidak ingin kehilangan pekerjaan dengan gaji yang bagus.

Variabel Achievement merupakan variabel keempat tertinggi, dengan nilai path coeffiecient sebesar 0,986 yang mempengaruhi motivasi kerja karyawan dan nilai koefisien determinasi 0,971. Menurut Dharma (2018)pencapaian positif termasuk dalam keberhasilan menyelesaikan tugas sulit tepat waktu, menyelesaikan masalah divisi atau memberi hasil positif pada suatu proyek. Pencapaian yang buruk berlaku sebaliknya dimana terjadi kesalahan pengerjaan dan buruknya pengambilan keputusan. Pencapaian di dalam perusahaan memicu karyawan memberi 
lebih,terlebih hasil pencapaian diakui oleh perusahaan serta perusahaan ini memiliki reputasi baik.

Variabel Award merupakan variabel kedua tertinggi, dengan nilai path coeffiecient sebesar 0,989 yang mempengaruhi motivasi kerja karyawan dan nilai koefisien determinasi 0,978 . Menurut Dharma (2018) penghargaan dari organisasi dalam bentuk gaji, bonus, maupun pengakuan atas pencapaian anggota dalam menyelesaikan tugas dan tanggung jawab, penghargaan ini memberi kepuasan bagi karyawan karena kerja keras bagi organisasi ini.

\section{Simpulan}

Berdasarkan dari hasil penelitian yang telah dilakukan, dapat disimpulkan bahwa work conditions, relationship with superiors, work safety, salary,achievement, danaward merupakan faktor yang mempengaruhi motivasi kerja pada karyawan PT Orela Shipyard. Hal diatas merupakan faktor-faktor yang mempengaruhi motivasi kerja karyawan PT Orela Shipyard. Jika diurutkan berdasarkan path coefficient, faktor-faktor tersebut dapat diurutkan dari yang tertinggi hingga terendah yaitu, salary, work safety, achievement,award, relationship with superiorsdan work condition.

\section{Saran}

Penelitian tidak dapat diterapkan secara langsung pada perusahaan maupun organisasi lain karena proses mengumpulkan data hanya untuk karyawan PT Orela Shipyard. Saran peneliti untuk para peneliti selanjutnya adalah menambah faktor motivasi kerja karyawan agar cakupan faktor yang mempengaruhi motivasi kerja karyawan semakin luas. Penelitian selanjutnya dapat dilakukan dengan metode yang berbeda seperti kualitatif atau analisis faktor yang berbeda.

\section{Daftar Pustaka}

Abdillah, W., dan Jogiyanto. 2015. Partial Least Square (PLS): Alternatif Structural Modeling (SEM) dalam Penelitian Bisnis. Yogyakarta: Andi.

Cahyani, I. D., Wahyuni, I., \& Kurniawan, B. 2016. Faktor-faktor yang berhubungan dengan motivasi kerja pada perawat rumah sakit jiwa (Studi Pada Bangsal Kelas III RSJD Dr. Amino Gondohutomo Provinsi Jawa Tengah). Jurnal Kesehatan Masyarakat (e-Journal), 4(2), 76-85.

Dharma, Y. 2018. The Effect of Work Motivation on the Employee Performance with Organization Citizenship Behavior as Intervening Variable at Bank Aceh Syariah. In Proceedings of MICoMS 2017 (pp. 7-12). Emerald Publishing Limited.

Ghozali, Imam. 2013. Aplikasi analisis mutivariate dengan program. Edisi ke 7. Semarang: Badan Penerbit Universitas Diponegoro.

Sugiyono. 2014. Metode Penelitian Kuantitatif. Bandung: Alfabeta.

Sutedjo, A. S., \& Mangkunegara, A. P. 2018. Pengaruh Kompetensi dan Motivasi Kerja terhadap Kinerja Karyawan di PT. Inti Kebun Sejahtera. BISMA (Bisnis dan Manajemen), 5(2), 120 129. 